\author{
ARTIGO \\ do/ https://doi.org/10.22481/rpe.v16i43.6760
}

\title{
O PAPEL DA UNDIME NO PROCESSO DE AFIRMAÇÃO DA LÓGICA DA GOVERNANÇA EM REDES NO CAMPO EDUCACIONAL BRASILEIRO
}

\author{
THE ROLE OF UNDIME IN THE PROCESS OF AFFIRMATION OF LOGIC FROM \\ GOVERNANCE IN NETWORKING IN THE FIELD OF BRAZILIAN EDUCATION
}

\section{EL PAPEL DE UNDIME EN EL PROCESSO DE AFIRMACIÓN DE LA LÓGICA DE LA GOBERNANZA DE REDES EN EL CAMPO EDUCATIVO BRASILEÑO}

\author{
Danilo Bandeira dos Santos Cruz \\ Universidade Federal de Santa Catarina - Brasil \\ Luciana Pedrosa Marcassa \\ Universidade Federal de Santa Catarina - Brasil
}

\begin{abstract}
Resumo: Este artigo é o resultado de uma pesquisa em andamento, cujo objetivo é o de analisar o (s) papel (is) da UNDIME no processo de definição e implementação de políticas educacionais no Brasil, no contex to de crise do capital e do consequente movimento de refuncionalização do Estado, no período de 1980 a 2020, com destaque à política curricular, expressa pela BNCC. De modo específico, coube a este texto, discutir o processo de instauração da governança no campo educacional brasileiro, diante do avanço do neoliberalismo nas últimas décadas do século XX. Nessa perspectiva, destacou-se o papel da União Nacional dos Dirigentes Municipais de Educação - UNDIME, na fundamental dinâmica de produção de consensos, junto aos sistemas e redes de ensino do país, com vistas à adesão destes, aos novos arranjos institucionais promovidos pelo paradigma da governança. Para tanto, a reflexão foi conduzida com base na concepção sobre Estado integral de Antonio Gramsci, além das considerações engelmarxianas, acerca do metabolismo capitalista. Ademais, o percurso reflexivo teve como estratégia metodológica, a análise qualitativa de documentos, com destaque ao estudo específico sobre o Caderno de Orientações ao Dirigente Municipal de Educação, elaborado em 2008 pela instituição investigada. Destarte, demonstrou-se a importante atuação da UNDIME no avanço de princípios e concepções empresariais na educação institucionalizada do país.
\end{abstract}

Palavras-chave: Educação. Governança. UNDIME.

\begin{abstract}
This article is the result of research in progress, the objective is to analyse the role(s) of UNDIME in the process of defining and implementing educational polices in Brazil, in the context of capital crises and the consequent refunctionalization movement of the State, from 1980 to 2020, with emphasis on the curriculum policy formulated by the BNCC. It was specifically up to this text to discuss the process of establishing governance in the field of Brazilian education, in the face of advance of neoliberalism in the last decades of the 20th century. In this perspective, the role of the National Union of Municipal Education Directors - UNIME was emphasised, in the fundamental dynamics of consensus production, along with the educational systems and networks of the country, with a view to their adherence, to the new institutional arrangements promoted by the governance paradigm. For this
\end{abstract}


purpose, a reflection was conducted based on Antonio Gramsci's concept of the Integral State, in addition to Engelmarxian considerations on the capitalist metabolism. Furthermore, the reflective path had as a methodological strategy, the qualitative analysis of documents, with emphasis on the specific study on the Guidance Book for the Municipal Director of Education, prepared in 2008 by the investigated institution. Therefore, the importance of UNDIME is demonstrated in the advancement of business principals and concepts in institutionalized education in the country.

Keywords: Education. Governance. UNDIME.

Resumen: Este artículo es el resultado de una investigación en curso, cuyo objetivo es analizar los roles de UNDIME en el proceso de definición e implementación de políticas educativas en Brasil, en el contexto de la crisis de capital y el consiguiente movimiento de refuncionalización del Estado, en el período de 1980 a 2020, con énfasis en la política curricular, expresada por el BNCC. Específicamente, dependía de este texto discutir el proceso de establecer la gobernanza en el campo educativo brasileño, en vista del avance del neoliberalismo en las últimas décadas del siglo XX. En esta perspectiva, se destacó el papel de la Unión Nacional de Directores de Educación Municipal - UNDIME en la dinámica fundamental de la producción consensuada, junto con los sistemas y redes educativas del país, con miras a su adhesión, a los nuevos arreglos institucionales promovidos por el paradigma gobernancia. Para este propósito, la reflexión se realizó con base en la concepción del estado integral de Antonio Gramsci, además de las consideraciones engelmarxianas sobre el metabolismo capitalista. Además, el camino reflexivo tuvo como estrategia metodológica, el análisis cualitativo de los documentos, con énfasis en el estudio específico sobre el Libro Guía para el Director Municipal de Educación, elaborado en 2008 por la institución investigada. Por lo tanto, se demostró el importante papel de UNDIME en el avance de los principios y conceptos empresariales en la educación institucionalizada en el país.

Palabras clave: Educación. Gobernancia. UNDIME.

\section{Introdução}

Ao final dos anos de 1990 e início dos anos 2000, as discussões acerca da constituição e funcionamento de redes de governança ${ }^{1}$ alcançou grande protagonismo, seja no âmbito acadêmico ou no campo da economia-política. Nota-se que, diante do ocaso da União Soviética, das crises do fordismo e do Estado de bem-estar social, houve o ascenso de formulações e de práticas neoliberais, cujas concepções, desde o final dos anos de 1930, já vinham disputando o debate na arena política.

Essa realidade foi constituída como expressão das grandes transformações materiais, decorrentes, antes de tudo, da crise estrutural do capitalismo nos anos de 1970, cujos desdobramentos promoveram uma série de ações interdependentes, dentre as quais se destacam: a reestruturação produtiva, com vistas ao aumento da produtividade e, por

\footnotetext{
${ }^{1} \mathrm{O}$ Estado modifica as suas tarefas, passando da condição de provedor para o de regulador e avaliador de políticas, muitas das quais a serem ofertadas por instituições privadas, numa perspectiva de descentralização e socialização da política. Assim, forma-se uma complexa rede de governança, que se constitui a partir do espraiamento das funções do governo, resultando na diminuição da fronteira entre o público e o privado (BALL, 2004).
} 
conseguinte, a retomada das taxas de acumulação; redesenho do Estado, fundamentado na chamada nova gestão pública ou administração gerencial, cuja estratégia prevalente esteve atrelada ao processo de descentralização, transferência de responsabilidades, privatização de empresas públicas, além de forte incentivo à participação de organizações da sociedade civil nas ações político-sociais. Tais características fazem parte de um conjunto de orientações atinentes à chamada governança em redes (SHIROMA; EVANGELISTA, 2014), desenvolvida como elemento de atualização da estratégia de manutenção e ampliação da hegemonia burguesa, em resposta às crises do Estado e da economia.

Desse modo, as influências de organizações da sociedade civil no processo de definição e realização de políticas públicas se tornaram cada vez mais intensas e comuns. Nesse cenário, quando se põe em tela o campo educacional, é preciso destacar o papel da União Nacional dos Dirigentes Municipais de Educação - UNDIME, uma associação civil sem fins lucrativos, que reune os Secretários de Educação dos municípios brasileiros em torno do debate educacional, como forma de fortalecer o posicionamento dos governos locais, junto ao poder central, ou seja, à União. Trata-se de uma entidade, criada entre os anos de 1985 e 1986 (NEVES, 2005), diante da dinâmica de transformações do mundo capitalista, em seu estágio de avanço do neoliberalismo, bem como por alterações no campo da administração pública, para o qual se exigia a implementação de uma nova gestão, pautada nos princípios empresariais do gerencialismo, como manifestação da inevitável alteração do papel do Estado. Concomitantemente, o Brasil procurava se adaptar a essas determinações internacionais, ao passo que seguia o seu movimento político de redemocratização, o qual se caracterizou pela permanente reivindicação relativa à garantia de abertura aos espaços de participação (NEVES, 2005).

Essas novas demandas, para alcançarem os resultados esperados pelos seus idealizadores, precisavam promover a adesão por parte do seu público-alvo, ou seja, a sociedade em geral, através da produção do convencimento. Caso contrário, não encontrariam terreno adequado para a sua concretização. Dessa forma, a estratégia prevalente foi e continua sendo a consolidação de uma ampla e complexa rede de atores das sociedades política e civil, que se articulam entre si e constituem muitos braços, distribuídos nas diferentes escalas internacional, nacional, regional e local. Considerando que é justamente nesta última que as políticas em geral devem alcançar aderência e, levando em conta a particularidade da política educacional brasileira, a UNDIME passou a desempenhar um papel fundamental de integração entre Secretarias Municipais de Educação e organizações situadas em outras 
escalas mais amplas, incluindo as organizações multilaterais, sobretudo, o UNICEF, seu principal parceiro internacional.

Nesses termos, a UNDIME tem promovido, em íntima parceria com os órgãos do Estado $^{2}$, contínuos processos formativos direcionados aos dirigentes e equipes técnicas das secretarias municipais de Educação, a fim de fomentar a socialização das políticas de educação, em geral, já definidas em outras instâncias. As estratégias usadas passam pela realização periódica de fóruns temáticos, seminários regionais, publicação de cadernos, guias de orientações, manuais, plataformas digitais, bem como jornais e outros informativos ${ }^{3}$.

Para se alcançar a compreensão da dinâmica de interferência da UNDIME na criação e realização de políticas educacionais, em primeiro plano, foi realizado um levantamento de bibliografia específica, voltado à análise crítica do sociometabolismo do capital e de sua relação dialética com os elementos da realidade social que o constitui, isto é, a articulação orgânica entre estrutura e superestrutura, a qual possibilitou, neste estudo, a percepção das transformações verificadas na unidade da economia com a política. Nesse sentido, a particularidade brasileira, no seu contexto contraditório de redemocratização, foi evidenciada, com base nas pesquisas realizadas por autores como Neves (2005), Shiroma e Evangelista (2014), Casimiro, (2014) e Viegas (2014), a partir das condições de possibilidades que favoreceram a criação da UNDIME, bem como a sua trajetória histórica de atuação política, apresentada de forma descritiva ao longo do texto.

De modo complementar e a fim de proceder à coleta dos dados, foram selecionados e analisados documentos oficiais, como o PDRAE - Plano Diretor da Reforma do Aparelho do Estado (1995) - e, fundamentalmente, o Caderno de Orientações ao Dirigente Municipal de Educação, elaborado pela UNDIME em 2008 e distribuído, desde então, às secretarias de educação, como uma espécie de manual do "bom gestor". Nesse documento, entre os seus seis capítulos, foi dada ênfase ao quinto, pois nele há um destaque mais explícito às orientações sobre a adoção da lógica da governança pelos gestores e suas respectivas equipes técnicas. Essas referências permitiram compreender tanto o processo de refuncionalização do

\footnotetext{
${ }^{2}$ Aqui, o Estado deve ser associado a "um equilíbrio da sociedade política com a sociedade civil" (ou hegemonia de um grupo social sobre toda a sociedade nacional, exercida através das organizações ditas privadas, como igrejas, sindicatos, as escolas, etc.) (GRAMSCI, 2011, p. 272). Em outros termos, Gramsci considera que "por 'Estado' deve-se entender, além do aparelho de governo, também o aparelho 'privado' de hegemonia ou sociedade civil". ${ }^{3}$ Entre 1986 e 2019, a entidade realizou 17 fóruns temáticos nacionais. Além disso, com vistas ao aperfeiçoamento atinente à Gestão dos Secretários municipais, a UNDIME formulou, entre outros materiais, a Agenda dos 100 Primeiros dias e o Caderno de Orientações aos Dirigentes Municipais de Educação, lançados em 2008 e reproduzidos, com alterações, a cada quatro anos (período de renovação das gestões nos municípios) (UNDIME, 2020).
} 
Estado, como o papel assumido pela instituição investigada, diante do movimento de socialização de políticas educacionais, assentadas na lógica da governança em rede ${ }^{4}$.

Finalmente, as reflexões, em geral, se ampararam nas contribuições teóricas de Marx e Engels, principalmente na abordagem sobre a estrutura do sistema do capital e as considerações indispensáveis de Antonio Gramsci acerca da relação dialética entre sociedade civil e sociedade política, em especial os seus direcionamentos a respeito do papel da sociedade civil no contexto de formulação das políticas públicas.

\section{Capitalismo em crise e estratégias atualizadas de reestruturação}

O capital se fundamenta, segundo Marx (1989), na exploração e apropriação do trabalho alheio. Os capitalistas, donos dos meios de produção, necessitam comprar e desfrutar da mercadoria força de trabalho, ou seja, dos sujeitos que compõem a classe trabalhadora, para produzir outras mercadorias. Nessa relação, o trabalhador recebe, em troca, um salário para a sua subsistência, enquanto produz as mercadorias em um tempo determinado, que é composto pelo trabalho socialmente necessário e pelo trabalho excedente, que corresponde à criação de mais-valia. Nesse sentido, o capitalista terá investido em matéria-prima, instrumentos de trabalho e nos salários dos seus trabalhadores, levando tais custos de produção ao valor final dos produtos, sempre em função da busca pelo lucro, o qual é obtido a partir do processo de exploração de força de trabalho, como trabalho não pago ou trabalho excedente. Sendo assim, nos valores das mercadorias deverão estar embutidos, ao final do processo, o capital constante, bem como o variável, isto é, o próprio salário do trabalhador, responsável por todo esse movimento de produção.

A etapa subsequente desse processo é a circulação, sem a qual a dinâmica do capital não seria completa. Entretanto, o sistema do capital não é apenas produtor, mas também reprodutor de ciclos, que garantem o acúmulo do capital e a sua perpetuação. Para que isso aconteça, a mercadoria socialmente produzida deverá ser trocada por dinheiro, que o capitalista reinveste na produção para o reinício de todo o processo produtivo. O dinheiro obtido no mercado deve possibilitar o surgimento do excedente de produção que, contraditoriamente, permite a intensificação de investimentos e, com isso, garante a oferta de mercadorias, maior acúmulo de

\footnotetext{
${ }^{4}$ Termo relacionado às articulações interinstitucionais, constituídas a partir do processo de socialização da política, através do qual diversas organizações da sociedade civil passaram a atuar, de modo mais estreito aos aparelhos de governo, na dinâmica de elaboração, realização e avaliação de políticas públicas. "Estado e organizações da Sociedade Civil atuam juntos na governança constituindo redes de políticas públicas" (SHIROMA; EVANGELISTA, 2014).
} 
capital, ao mesmo tempo em que se torna uma barreira para esse processo, pois o excedente pode se transformar em excesso de mercadorias (oferta) para um mercado consumidor tendencialmente restrito (baixa demanda), resultando na desvalorização dos produtos e na queda das taxas de acumulação de capital. Para Catani,

Quando nem todas as mercadorias da empresa conseguem ser escoadas para o mercado e transformadas em dinheiro, ocorre uma diminuição da acumulação. O processo de acumulação capitalista segue uma trajetória de constantes altos e baixos, onde períodos de negócios florescentes alternam-se com a estagnação e as quebras do mercado [...] (1998, p. 38).

Destarte, no sociometabolismo do capital se faz presente uma contradição fundamental, expressa, por um lado, pelo processo ampliado de produção de mercadorias e, por outro, complementar a este, pela apropriação privada dos produtos. Essa dinâmica se reverbera no movimento de superprodução de mercadorias, na permanente concentração de capital, no subconsumo, no aumento da população desempregada, na expansão da pobreza, assim como na tendencial queda da taxa de lucros, somado ao acirramento da luta de classe. Tais determinações corroboram a explicação acerca das múltiplas causas das crises, as quais devem ser entendidas como parte indissociável do próprio processo de desenvolvimento do capitalismo.

Nesse direcionamento, o esgotamento de determinado processo de acumulação faz emergir e aprofundar as crises estruturais e exige uma combinação de medidas para o reestabelecimento do equilíbrio do sistema, o que resulta no surgimento de um novo regime de acumulação, como ocorreu com o desenvolvimento da chamada acumulação flexível, após a crise do petróleo de 1973 (BASTOS, 2014). Em tal contexto de profundas transformações, o Estado é pressionado pela classe burguesa a imprimir uma série de reformas, capazes de favorecer a retomada das taxas de lucro, fato verificado, por exemplo, quando do ocaso do fordismo, conforme indica Harvey:

As políticas Keynesianas tinham se mostrado inflacionárias à medida que as despesas públicas cresciam e a capacidade fiscal estagnava. Como sempre fora parte do consenso político fordista que as redistribuições deviam se fundamentar no crescimento, a redução do crescimento significava inevitavelmente problemas para o Estado de bem-estar social e do salário social. Os governos de Nixon e de Heath tinham reconhecido o problema no período 1970-1974, iniciando lutas contra o trabalho organizado e reduções das despesas governamentais (2006, p. 157).

Foi nessa atmosfera de decadência do fordismo e do Estado de bem-estar social que o mundo viu os governos de diferentes países estabelecerem profundas e amplas reformas, que atingiram, de alguma maneira, todos os setores da administração pública, numa perspectiva 
pautada em políticas de austeridade e influenciadas diretamente pelas teorias de grandes intelectuais liberais, como Friedrich Hayek, Karl Popper, Milton Friedman e James Buchanan (BRESSER-PEREIRA, 2017, p. 698 apud FREITAS 2018, p. 13). Essa influência, associada às condições materiais, que caracterizaram o período de ocaso da União Soviética, bem como do fordismo e a emergência do regime de acumulação flexível nos anos de 1970-1980, favoreceu o ascenso de governos como o de Thatcher, na Inglaterra, e Reagan, nos Estados Unidos, assentados na perspectiva neoliberal.

Nesse período, são formulados novos modelos administrativos pela iniciativa privada e adotados, em primeiro plano, pelos governos de países centrais e, em seguida, por países periféricos, como estratégia para superação da crise do capitalismo, fundamentados em princípios gerencialistas que reverberaram na alteração das funções do Estado. Tais modelos estão baseados numa dinâmica de gestão intergovernamental, configurada por uma rede complexa e mais ampla de atores, articulados e distribuídos em espaços para além da esfera estatal (sociedade política), porém intimamente conectados a esta, dando origem a fenômenos como a "nova gestão pública" e a governança em rede, como desdobramento do movimento de "socialização do poder político, que teve como moldura um processo contraditório de socialização do trabalho e a apropriação aguda da riqueza socialmente produzida" (NEVES, 1994), num cenário marcado por intensos debates no âmbito do Estado stricto senso e da sociedade civil acerca das políticas sociais, entre as quais, da educação.

\section{A governança em redes como elemento estratégico de manutenção da hegemonia burguesa: o papel da UNDIME}

No contexto histórico correspondente à última década do século passado e início do XXI, a discussão acerca das "redes de políticas públicas e novas formas de governança" alcançou maior destaque, "com as mudanças no ideário socialdemocrata clássico que incorporou elementos desenvolvimentistas às formulações e às práticas neoliberais" (SHIROMA; EVANGELISTA, 2014, p. 22). Com efeito, é possível afirmar, com base em Harvey (2014), que alguns dos formuladores do receituário neoliberal propagado especialmente durante o Consenso de Washington passaram a defender um redesenho do Estado, capaz de promover uma maior coesão entre as classes sociais. Para tanto, era necessário buscar a combinação entre livre mercado e justiça social, a qual passaria da responsabilidade restrita, por parte da sociedade política, para a jurisdição de organizações da sociedade civil, através das parcerias público-privadas.

Com essa tendência, as relações de interdependência entre organismos multilaterais, 
Estados-nação e organizações da sociedade civil, se tornaram ainda mais estreitas e isto se manifestou no surgimento de um grande número de aparelhos de ação política e ideológica (CASIMIRO, 2018), atuando no processo de definição, socialização, implementação e avaliação de políticas públicas. Nessa perspectiva, marcada pelo protagonismo da governança em redes, a sociedade política, em íntima articulação com a sociedade civil, desempenhou um importante papel e, a sua atuação, articulada, fundamentada em relações interinstitucionais, extrapolou os limites territoriais das diferentes nações.

Esse novo arranjo da gestão pública corroborou o movimento de municipalização, caracterizado pela transferência de atribuições da esfera federal para a municipal, fato que acabou por induzir "as parcerias e o fortalecimento das ideias de "empoderamento" e de "protagonismo local” (SHIROMA; EVANGELISTA, 2014, p. 24). Nesse sentido, sob o discurso da necessária reestruturação do Estado, com vistas à melhoria da sua eficiência, o Brasil incorporou as orientações de organismos multilaterais, como o Banco Mundial, e adotou a perspectiva da governança em redes, ocorrida em 1995, sob a liderança de Bresser Pereira, então Ministro da Administração e Reforma do Estado na gestão do ex-Presidente Fernando Henrique Cardoso (1995-2003).

Nessa direção, foi estabelecido o Plano Diretor da Reforma do Aparelho do Estado, mecanismo legal, formulado com o intento de orientar as reformas a serem realizadas ao longo dos anos de 1995-1998 no campo da administração pública brasileira. Entre as justificativas para o reajuste do Estado, destaca-se a seguinte:

Pretende-se reforçar a governança - a capacidade de governo do Estado através da transição programada de um tipo de administração pública burocrática, rígida e ineficiente, voltada para si própria e para o controle interno, para uma administração pública gerencial, flexível e eficiente, voltada para o atendimento do cidadão. (BRASIL, 1995, 13).

Nota-se, com isso, a estratégia discursiva da negação do burocratismo estatal, a partir da sua associação à ineficiência, ao mesmo tempo em que se proclama a necessária transição a uma nova gestão pública, embasada no gerencialismo, tendo em vista o alcance da eficácia e, por conseguinte, do melhor atendimento ao cidadão. Por tal via, a sociedade em geral é posta como público-alvo, diante de uma construção ideológica voltada a eclipsar os interesses mais amplos do capital. Não se trata da negação completa das demandas societárias, visto que, no âmbito da estratégia de dominação burguesa, há de se fazer alguns "sacrifícios de ordem econômico-corporativa" (GRAMSCI, 2000), ou seja, algumas concessões aos trabalhadores para se garantir a coesão social. 
Na esteira dessa reflexão, é preciso afirmar que a noção de nova gestão pública e, por tabela, de nova governança, se refere a uma lógica de governo configurada pela atuação conjunta de diversos organismos, situados no âmbito da sociedade civil e denominados, pela literatura liberal, de organizações públicas não estatais. Assim, ficou conhecido, no Plano Diretor de Reforma do Aparelho do Estado - PDRAE, o conjunto de instituições sem fins lucrativos que se guiariam no sentido de atender ao interesse público, aos quais foi dada ampla abertura para o desenvolvimento de atividades antes exclusivas ao Estado (BRASIL, 1995). À vista disso, Shiroma e Evangelista (2014, p. 27) pontuam que "a governança em rede também é conhecida como anglo school governance e refere-se a formas de regulação em que as políticas públicas são desenvolvidas não exclusivamente pelo Estado”.

Parte-se do pressuposto de que a esfera estatal "compreende e abarca as organizações da sociedade civil que, desta feita, ampliam sua estrutura de dominação" (CASIMIRO, 2018, p. 19). Destarte, somente um Estado percebido e analisado em seu sentido orgânico mais amplo pode oferecer os elementos materiais capazes de promover o entendimento acerca do complexo movimento de manutenção e ampliação do capital, sobretudo, no contexto contemporâneo, marcado pela presença e influência, cada vez mais intensas, de organizações da sociedade civil nas decisões de diferentes governos. Dessa forma, assumimos a concepção de Estado, tal como anunciado antes, que é apresentada por Gramsci como a relação dialética entre sociedade política e sociedade civil, ou seja, "hegemonia couraçada de coerção" (GRAMSCI, 2000).

Nessa direção, o Estado possui um papel essencial de educador, voltado à conformação dos modos de agir-pensar dos sujeitos, tendo em vista a perpetuação da visão de mundo defendida pelas classes dirigentes, numa lógica voltada à universalização dessa forma particularizada de perceber e participar do mundo, isto é, plenamente alinhada aos ideais da burguesia, mas projetada como concepção geral de toda sociedade. Isto ajuda a compreender, nos termos de Gramsci (2011), o fenômeno do consentimento ativo, capaz de levar os membros da classe que vive de sua força de trabalho à reprodução permanente da sua própria condição de subsunção ao capital e, nesse sentido, da intensa dinâmica de exploração a que estão submetidos, sem que, no entanto, esse processo seja, por tais homens, percebido como histórico e, portanto, possível de ser superado.

Sendo assim, pela via da constituição do consenso, sempre atrelado à coerção, o sistema de ideias, somado ao comportamento dos indivíduos sociais, é condicionado, principalmente, com base em concepções dominantes, que se estabelecem com uma forte influência da sociedade civil, representada por seus aparelhos privados de hegemonia, isto é, instituições comprometidas com a propagação de um sistema de ações e ideias direcionadas à conquista e 
manutenção da hegemonia, assim como por seus intelectuais orgânicos, possuidores de capacidade técnica e dirigente ${ }^{5}$, os quais têm atuado, de modo cada vez mais presente e incisivo, nos processos de concepção, divulgação e efetivação de políticas públicas, desenhadas na contemporaneidade, preponderantemente, a partir dos moldes do neoliberalismo, apesar das resistências e lutas travadas pela classe trabalhadora. Assim, a produção de consensos, que em última instância é uma manifestação de interesses econômicos, constitui-se ainda como importante determinação de cunho político e ideológico. Trata-se, portanto, de um movimento dialético, em que a via ideológica complementa os aspectos econômicos e políticos e estes, aquela, corroborando o movimento de dominação burguesa.

\section{Governança no campo educacional e o papel da UNDIME}

Viegas (2014), em sua tese de doutorado, intitulada O Mercado da Formação Continuada de Professores no Brasil: a Presença do Empresariamento Social Privado, apresenta uma importante contribuição sobre a capilaridade alcançada pela perspectiva do gerencialismo no campo educacional brasileiro e a participação de entidades representativas como a UNDIME e o CONSED nesse processo. Em seu estudo, a autora demonstra como essas formas dominantes de agir/pensar na/a realidade, têm se tornado cada vez mais comuns e vêm alcançando a adesão dos diferentes sistemas e redes de ensino do país. Com isso, o modelo gerencial da governança em rede ganha força, sobretudo, no âmbito das secretarias estaduais e municipais de educação. Dão evidência a esse processo: as avaliações de desempenho, aplicadas aos professores e demais profissionais da educação, as quais têm sido cada vez mais exigentes; os planos e programas de avaliação, os quais buscam se aproximar aos modelos propostos pelas avaliações externas, cuja centralidade tem sido a aprendizagem rudimentar de conteúdos voltados ao pragmatismo, que agregam pouca contribuição ao pensamento crítico; a dinâmica de responsabilização, que direciona aos sujeitos das escolas os fracassos e sucessos alcançados por eles de modo isolado e medidos por avaliações padronizadas; o maior ou menor volume de recursos financeiros a serem distribuídos às unidades de ensino, de acordo com o alcance ou não de suas metas, previamente estabelecidas; entre outros aspectos. Esta configuração não é algo aleatório, mas trata-se da consequente dinâmica de descentralização governamental, adotada no Brasil ao longo dos anos de 1990, fundamentada pela reforma do

\footnotetext{
${ }^{5} \mathrm{O}$ intelectual orgânico deve ser um "organizador de massas de homens". Intelectual aqui, expressa o sentido da capacidade de direção de um grupo social e não como o senso comum apreende, isto é, como intelectualismo. "Por isso, seria possível dizer que todos os homens são intelectuais, mas nem todos os homens têm na sociedade a função de intelectuais" (GRAMSCI, 2011, p. 206).
} 
Estado, o que levou ao aumento da responsabilidade de Estados e municípios e promoveu a proliferação de organizações sociais, principalmente de cunho empresarial, em busca de parcerias com o setor público.

Nessa arena política, caracterizada pela permanente correlação de forças, as parcerias público-privadas vêm favorecendo as estratégias de manutenção da hegemonia burguesa, traçadas e realizadas também por dentro da educação institucionalizada. Para tanto, organizações de natureza empresarial têm atuado em articulação com um grande conjunto de atores situados dentro e fora da sociedade política. Trata-se de um considerável número de Fundações Privadas e Associações sem Fins Lucrativos - FASFIL ${ }^{6}$, criadas no país, prevalentemente a partir dos anos de 1990. A título de exemplo, destacam-se a Fundação Lemann, a Fundação Telefônica/Vivo, o Instituto Natura, o Itaú Social, a Fundação Santillana, o movimento Todos pela Educação, o Instituto Ayrton Senna, entre outros. A atuação desse conjunto de organismos se dá de modo articulado, em rede, e aponta para o objetivo de participar na definição, implementação e avaliação de políticas educacionais. Foi nesse direcionamento que se produziu a política expressa pelo Compromisso Todos Pela Educação, instituído pelo Decreto No 6094/2007, como resultado do forte poder de influência apresentado por esses aparelhos de hegemonia de cunho empresarial com destaque ao movimento Todos Pela Educação - TPE (VIEGAS, 2019).

Somado a isso, percebe-se, sobretudo a partir do processo de redemocratização do país, combinado ao movimento de socialização da política, o surgimento de organizações da sociedade civil, constituídas por agentes políticos, as quais foram criadas a fim de estabelecer uma articulação intergovernamental, tendo em vista a ampliação dos espaços de participação a partir do estreitamento das relações entre as diferentes esferas de governo. Dois desses atores são o Conselho Nacional de Secretários Estaduais de Educação - CONSED e a União Nacional dos Dirigentes Municipais de Educação - UNDIME, objeto de nosso estudo. A UNDIME se define como uma associação civil, sem fins lucrativos, que atua como instância representativa dos Secretários Municipais de Educação do Brasil.

O contexto de surgimento da UNDIME está relacionado, portanto, ao movimento de transição ao regime democrático no país e ao movimento de municipalização, decorrente da política de descentralização governamental, proposta pela reforma do aparelho do Estado. Inicialmente, a sua pauta preponderante esteve atrelada justamente à defesa da autonomia dos municípios, tendo em vista a promoção do desenvolvimento local, de forma menos subjugada

\footnotetext{
${ }^{6}$ De acordo com o IBGE, em 2016 havia no Brasil 236.950 FASFILS, dentre as quais, 15.828 correspondiam ao campo da educação e pesquisa (IBGE, 2016).
} 
às determinações das esferas estadual e federal, sobretudo, no que se refere às transferências de recursos. Nesse sentido, a associação, criada em outubro de 1986, após a articulação entre representantes do Ministério da Educação e de Secretários e Prefeitos da Região Metropolitana de Pernambuco, passou a influenciar nos direcionamentos das políticas educacionais brasileiras de modo cada vez mais intenso (MALHEIROS, 2006).

Com efeito, a UNDIME participou ativamente de debates em torno das pautas atinentes às políticas educacionais do país, se constituindo em importante influenciadora das decisões governamentais, assim como exercendo uma tarefa indispensável na produção de consensos. Na década de 1990 destaca-se a sua contribuição à elaboração da Lei № 9.394/1996 (Lei de Diretrizes e Bases da Educação - LDB), bem como da Lei 9.424, de 24 de dezembro de 1996, que dispôs sobre o Fundo de Manutenção e Desenvolvimento do Ensino Fundamental e de Valorização do Magistério - FUNDEF. Um ano antes, a instituição também contribuiu na construção do Programa Dinheiro Direto na Escola - PDDE, o qual fez parte das medidas voltadas ao movimento de descentralização governamental.

As principais estratégias definidas pela UNDIME no processo de elaboração e socialização de políticas educacionais são a realização de parcerias diretas com o Ministério da Educação e outras organizações das sociedades política e civil, inclusive de cunho empresarial, bem como a promoção de discussões, através de fóruns temáticos, realizados regional e nacionalmente. Somado a isso, a entidade elabora materiais impressos, como guias de orientações aos dirigentes municipais de educação de todo o Brasil, pequenos jornais e informativos. Nesse sentido, ao se considerar a ausência de identidade com a maioria das políticas de educação, por parte dos profissionais da área situados no âmbito municipal, haja vista o fato de não terem participado de sua formulação, percebe-se a importância de se definir uma ampla e estratégica rede de agentes, capazes de alcançar e convencer esses sujeitos em suas localidades, ou seja, no seu campo concreto de atuação (REBECCA TARLAU e KATHRYN MOELLER, 2020).

A UNDIME cumpre bem esse papel, como tão lucidamente demonstrou Viegas (2014), assim como Tarlau e Moeller (2020), já que os seus permanentes eventos e demais estratégias conseguem atingir Dirigentes e equipes técnicas das Secretarias Municipais de Educação, em sua maioria, pouco familiarizados com o metabolismo técnico dos sistemas e redes de ensino que representam. Isto, porque as alterações político-partidárias ocorridas no interior das secretarias são muito grandes e constantes, o que desfavorece o amadurecimento da experiência necessária para a condução dos trabalhos de gestão, de forma autônoma. Assim, essas equipes se tornam dependentes de orientações externas e isto favorece o fortalecimento do intercâmbio 
com a UNDIME. Somente em janeiro de 2013, por exemplo, mais de 70\% dos municípios do país alteraram as equipes técnico-administrativas das suas Secretarias de Educação, em razão das mudanças de gestores municipais, proporcionada pelas eleições de outubro do ano anterior (UNDIME, 2012b). Destarte, a atuação dessa importante entidade representativa dos Secretários de Educação, está associada ao essencial efeito multiplicador que ela proporciona, em relação à socialização de políticas educacionais, muito embora esse processo, de forma concomitante, reflita contradições, distorções e resistências ao longo do seu movimento de efetivação. Prova disso são os inúmeros protestos de estudantes e professores contrários às reformas educacionais, como a do Ensino Médio, que em 2016 levou à ocupação de várias escolas públicas, por parte desses importantes sujeitos históricos, prevalentemente, pela iniciativa dos primeiros.

Com efeito, diante da sua relevância nessa complexa relação de desenvolvimento de políticas de educação, a UNDIME seguiu, desde a sua formação inicial, estabelecendo as suas articulações na condição de componente de uma complexa rede de sujeitos coletivos, envolvidos com a temática educacional, conforme informações da própria entidade:

Diante das novidades da LDB e do Fundef, a Undime realiza o $6^{\circ}$ Fórum Nacional. Na pauta, a trajetória da Undime, as contribuições dos organismos internacionais para a educação básica, financiamento da educação, diretrizes curriculares nacionais. Durante as atividades do Fórum, é realizado o Ato em Defesa da Escola Pública de Qualidade no Congresso Nacional. Também em 97, é promovido o curso "A educação municipal a caminho da autonomia", considerado como precursor do Programa de Apoio aos Secretários Municipais de Educação - Prasem. No mesmo ano, a Undime integra a discussão das duas propostas em torno do Plano Nacional de Educação. Uma do Ministério da Educação e a outra da sociedade civil. Também em 97 é criada a seccional da Undime no AM (UNDIME, 2020).

Apesar de buscar debater, desde sua constituição em 1986, diferentes temáticas atinentes ao campo educacional, como financiamento da educação, Plano Nacional de Educação, Censo Escolar, entre outros, a centralidade dos debates travados pela UNDIME nas duas últimas décadas do século passado esteve mais atrelada à dinâmica de descentralização governamental, isto é, ao processo de municipalização. Uma necessidade produzida no contexto da expansão neoliberal pelo mundo e de suas respectivas estratégias voltadas à reestruturação do Estado, cuja caracterização pode ser descrita como um esgarçamento da sociedade civil, através do exponencial desenvolvimento de inúmeras organizações, sobretudo empresariais, que passaram a assumir o gerenciamento de direitos sociais a partir dos seus "projetos privados". Um movimento que teve/tem por corolário o fortalecimento de "entidades, fundações e institutos privados" na disputa pelos fundos públicos (CATINI, 2017, p. 37). 
Já na primeira década do século XXI, as temáticas dos fóruns, bem como alguns documentos orientadores elaborados pela UNDIME, em parceria com outras organizações, como a Fundação Santillana da Editora Moderna, o Fundo das Nações Unidas para a Infância - UNICEF e o MEC, voltaram-se à formação dos gestores educacionais, em especial, dos Secretários Municipais de Educação. Para tanto, em 2008, foi criado o Caderno de Orientações ao Dirigente Municipal de Educação: Fundamentos, Políticas e Práticas, assim como a Agenda dos 100 Primeiros Dias, os quais foram republicados em 2012 e em 2016, com revisões e ampliação de conteúdo. Ao se analisar o teor de tais publicações, em especial, dos Cadernos de Orientações, é possível identificar algumas características das concepções teóricas neoliberais, pautadas na lógica da administração gerencial, da nova gestão pública e da boa governança. O documento em questão está organizado em seis capítulos, sendo que o quinto foi dedicado exclusivamente à temática da governança, conceituada pelos autores da seguinte maneira:

Pode-se afirmar que o conceito de governança ultrapassa os limites da ação burocrática de qualquer Dirigente Municipal de Educação (DME) comprometido com o processo de gestão democrática. $\mathrm{O}$ que se tem na atualidade é uma diversidade de fatores que poderão auxiliá-lo no desenvolvimento de suas atribuições. As necessidades solicitam de um DME ações articuladas com outros atores sociais, ações muito mais amplas que as questões meramente burocráticas, que também são necessárias para o andamento de boa parte dos processos decisórios. Com ações de bom relacionamento com os diversos setores, um DME passa a ser visto como um líder capaz de articular parcerias e políticas públicas (UNDIME, 2012,p. 122).

Como se vê, a argumentação segue a mesma linha presente no Plano Diretor da Reforma do Aparelho do Estado de 1995-1998, no qual a superação da burocracia e a articulação com outros atores da sociedade são postos como condições necessárias ao alcance da eficiência na gestão. Assim, a UNDIME passou a destacar a importância dos gestores municipais atuarem em rede, estabelecendo parcerias com diferentes entidades da sociedade civil para o desenvolvimento de políticas públicas, fato que contribuiu fortemente para a efetivação das parcerias público-privadas, além de induzir a realização de contratos de gestão entre Secretarias municipais e organizações de cunho empresarial.

O discurso ideológico, presente no texto analisado, segue enfatizando a condição indispensável de se estabelecer relações de parceria entre o setor público e organizações sociais, haja vista a impossibilidade de o governo atuar sozinho, em dadas circunstâncias. Por essa linha, se destaca:

Mediante as experiências de ações em parceria, o setor público e a sociedade aprendem a somar esforços na busca de soluções para um melhor atendimento 
à sociedade, adentrando em situações nas quais o governo não tem condições de atuar sozinho (UNDIME, 2008, p. 126).

Ademais, fica perceptível, a tentativa de se eclipsar a existência de elos entre determinadas organizações da sociedade civil, denominadas "organizações de interesse público não estatais" e do campo empresarial. Para tanto, a princípio, se estabelece a divisão entre instituições governamentais, empresariais e do chamado Terceiro Setor para, em seguida, elencar um conjunto de características definidas como próprias deste último. Antes, enaltece o papel social dessas organizações, conforme o trecho em destaque:

Tendo como objetivo o desenvolvimento político, econômico, social e cultural no território de sua atuação, as instituições ligadas ao terceiro setor têm características próprias que as diferenciam de instituições governamentais (primeiro setor) e empresariais (segundo setor), a saber:

- são formalmente constituídas;

- sua estrutura básica é não governamental, ou seja, não são ligadas institucionalmente a governos;

- realizam a própria gestão, não sendo controladas externamente;

- não têm fins lucrativos, portanto, a geração de lucros ou de excedentes financeiros deve ser reinvestida integralmente na organização; e

- devem possuir, em algum grau, mão de obra voluntária, ou seja, não remunerada [...] Hoje, o conceito de terceiro setor começa a se ampliar para além do círculo das ONGs e OSCIPs, valorizando outros fatores e serviços, como a responsabilidade social empresarial; as associações beneficentes e recreativas; as iniciativas das igrejas; e o trabalho voluntário. Tais instituições podem ser importantes parceiras da Educação municipal, sem, contudo, substituir o papel da Secretaria Municipal de Educação (UNDIME, 2008, p. 126 , grifo nosso).

A UNDIME incentiva ainda parcerias com os movimentos e conselhos sociais, além dos fóruns de educação. Assim, percebe-se que os intercâmbios entre organismos multilaterais, Estados, bem como grupos empresariais organizados em seus aparelhos privados de hegemonia vão se intensificando e, de modo complementar, vai se estabelecendo, no âmbito nacional, uma dinâmica de "descentralização, flexibilização e fortalecimento de organizações da sociedade civil”, as quais se voltam à efetivação de acordos, com o propósito de garantir as "condições de governabilidade sob os auspícios do Capital" (SHIROMA; EVANGELISTA, 2014, p. 24).

Nesse arranjo, a UNDIME tem desempenhado um papel fundamental de interlocutor, participando ativamente da formulação e implementação de políticas educacionais, além de atuar na condução do movimento formativo de dirigentes municipais de educação. Sendo assim, essa associação da sociedade civil tem contribuído, sobremaneira, com o fundamental processo de convencimento, haja vista a condição de legitimidade alcançada por tal entidade, junto aos municípios brasileiros. 
A título de exemplo mais recente, cita-se a participação direta da entidade em tela na execução do Plano Nacional de Educação - PNE e, preponderantemente, dos Planos Municipais de Educação - PME, os quais, para serem formulados, implementados, monitorados e acompanhados pelas instâncias locais, exigem a participação de Secretários de Educação, juntamente com as suas equipes técnicas, em permanentes processos formativos oferecidos por intelectuais orgânicos, representantes da UNDIME (PEREIRA E JÚNIOR, 2016). Para esse movimento, o Ministério da Educação, através de sua Secretaria de Articulação com os Sistemas de Ensino - SASE, criou uma Rede de Assistência Técnica, composta pelo MEC, pelas Secretarias Estaduais de Educação e pela UNDIME.

A importante contribuição da UNDIME foi destacada no dia 14 de setembro de 2014, quase dois meses após a sanção do Plano Nacional de Educação - PNE, Lei No 13005/2014, pelo Ministério da Educação, que publicou em seu site oficial uma notícia atinente à elaboração dos PMEs, enfatizando a importância da parceria com organizações como o Conselho de Secretários Estaduais de Educação - CONSED, a União Nacional dos Dirigentes Municipais de Educação, o Conselho Nacional de Educação - CNE e a União Nacional dos Conselhos Municipais de Educação - UNCME. Na ocasião o então titular da pasta, o Senhor Binho Marques afirmou:

A parceria para a execução do PNE, construção e aprovação dos planos estaduais e municipais reúne o Conselho Nacional dos Secretários de Educação (Consed), a União Nacional dos Dirigentes Municipais de Educação (Undime), o Conselho Nacional de Educação (CNE), o Fórum dos Conselhos Estaduais de Educação, a União Nacional dos Conselhos Municipais de Educação (Uncme) (BRASIL, 2014).

Como se vê, a UNDIME se coloca como uma importante organização que expressa a ideia de defensora dos interesses gerais do campo educacional. Uma "defensora/representante formal" da educação, que aparentemente age com neutralidade e, portanto, de maneira legítima para garantir o alcance de interesses sociais mais amplos. Entretanto, pela sua articulação e vinculação aos interesses empresariais, ela exerce uma função estratégica de construção de consensos e perpetuação da hegemonia burguesa no Brasil. Um país assim, de dimensões territoriais continentais, constituído por 5.700 municípios, depende de uma rede sincronizada de atores, capazes de promover a adesão das políticas formuladas pelo Estado. Assim, a atuação, com base na formulação e realização de políticas sociais, precisa se dar em escalas diferenciadas. Nessa rede, alguns organismos estão mais distantes, outros mais próximos dos espaços de materialização dessas políticas, isto é, os municípios. Dessa maneira, vários braços vão sendo formados para alcançarem esses espaços e a UNDIME é parte indissociável dessa 
dinâmica, participando como entidade influente na esfera da educação, corroborando a construção de consensos junto aos municípios.

Por essa lógica, o Estado transfere a sua responsabilidade de provedor de políticas sociais ao chamado "terceiro setor", como parte da atualização das estratégias de dominação burguesa, o que resulta no redesenho das funções das sociedades política e civil.

As relações entre agências supranacionais, Estados e grandes corporações se estreitaram conduzindo a um movimento externo de integração a blocos econômicos, simultaneamente a um movimento interno de descentralização, flexibilização e fortalecimento de organizações da Sociedade Civil, direcionadas à composição de novos pactos para assegurar condições de governabilidade sob os auspícios do Capital. Essas relações evidenciaram-se na maior presença de grupos privados na definição e execução de políticas públicas configurando o crescimento do chamado "terceiro setor", representado por organizações e fundações empresariais. Recrudesceram-se as disputas de classes e frações de classe no âmbito da governabilidade para a definição das prioridades na agenda da política social e econômica (CARVALHO, 1999, p. 24 apud SHIROMA; EVANGELISTA, 2014, p. 24).

Como se vê, a reflexão das autoras acima permite afirmar que o Estado se tornou mais extenso, passando a atuar de modo pactuado com diversas organizações da sociedade civil, em conformidade às demandas mais amplas do capital. Nesse arranjo, a UNDIME tornou-se parte indissociável, por se figurar como um importante elo de integração com os municípios do país, em relação às políticas educacionais. Por tal razão, a sua trajetória revela uma atuação cada vez mais articulada com o Ministério da Educação, assim como com outras instituições da sociedade civil, sendo as mais importantes aquelas definidas como os seus principais parceiros institucionais. No âmbito nacional, destacam-se os seguintes intelectuais coletivos: a Fundação Lemann, o Itaú Social, o Instituto Natural, a Fundação Santillana, a Fundação Telefônica Vivo e o Instituto Alana. Internacionalmente o seu maior parceiro, como já informado, é o Fundo das Nações Unidas para a Infância - UNICEF (UNDIME, 2020).

Nesse sentido, o que há é um crescente incentivo às parcerias público-privado, o que favorece a indústria dos livros e de outros materiais didáticos, assim como as empresas de consultorias, além de reduzirem os investimentos nos serviços sociais, ao passo que se elevam as transferências de recursos públicos à esfera privada, como expressão da dura disputa pelo fundo público, isto é, pela parcela de mais-valia, convertida em impostos e capturada pelos governos. Ademais, parte dos recursos subtraídos do campo público vai para o pagamento da dívida pública, que se tornou um importante instrumento de reprodução ampliada e de reequilíbrio do sistema capitalista, haja vista a conversão de títulos públicos em mercadorias mais seguras e rentáveis, a serem adquiridas no mercado financeiro, como componente do 
sistema de crédito. Na esteira desse movimento, percebe-se, segundo Santos (2018), a multiplicação das ações das grandes corporações, de modo geral e, de modo específico, daquelas, cujos investimentos estão mais voltados à educação.

Como exemplo, destaca-se, no contexto nacional, a rápida expansão de grandes grupos empresarias, que em 2007 passaram à abertura de capital na bolsa de valores, num período em que o Governo Federal transferiu grande volume de recursos à iniciativa privada, através da ampliação do Fundo de Financiamento Estudantil. Enquanto os lucros dessas empresas cresciam exponencialmente, o ensino público, sobretudo, o superior, se tornava ainda mais precarizado (SANTOS, 2018).

Com o redesenho do Estado propagou-se a ideia da responsabilidade social das empresas, bem como se produziu a sensação de que à sociedade passou a ser oferecido um espaço de participação ativa, capaz de promover a materialização do interesse coletivo no âmbito do Estado. No plano concreto, um dos efeitos produzidos foi a atenuação dos conflitos sociais, visto que houve um ilusório equilíbrio de forças no campo das disputas entre as classes. Essas concepções, formuladas pelas frações de classe que se constituem no bloco no poder (POULANTZAS, 2015), são corroboradas por importantes aparelhos privados de hegemonia, socializadas por intelectuais orgânicos e contam com uma participação indispensável da União Nacional dos Dirigentes Municipais de Educação.

Com isso, compreendemos as formas de atuação de organizações da sociedade civil, ligadas ao campo educacional, com destaque à União Nacional dos Dirigentes Municipais de Educação - UNDIME, visto que, a esta instituição, atribui-se um papel legítimo de mediadora e representante dos interesses sociais. Nota-se que, em diferentes circunstâncias, tal entidade tem adotado ações estratégicas, voltadas ao plano de difusão e reprodução do sistema de ideias neoliberais, tendo em vista, sobretudo, a formação de consensos, no sentido de promover a naturalização da sociabilidade capitalista e, de modo complementar, combater ideologias contrárias ao projeto de dominação hegemônico. Isto, sob o manto ideológico da neutralidade e com a complementariedade dos mecanismos de coerção promovidos pela sociedade política.

\section{Considerações Finais}

O propósito deste texto foi o de tecer considerações relativas ao processo de implantação da perspectiva neoliberal da governança em redes no interior da educação institucionalizada brasileira. O contexto de surgimento de tal demanda é o da reestruturação produtiva, ocorrida após a crise estrutural do capital dos anos de 1970, momento em que a 
chamada acumulação flexível se torna a alternativa prevalente no movimento de busca pela retomada das taxas de acumulação.

Nessa direção, o Estado passou por um profundo redesenho, voltado à lógica da descentralização, à transferência de responsabilidades para outras instâncias da sociedade, à privatização de empresas públicas, o que resultou na sua refuncionalização, com a promoção da socialização da política reverberando no surgimento de inúmeras organizações da sociedade civil. Nessa nova configuração, houve a proliferação de organizações da sociedade civil que passaram a assumir ações político-sociais, até então, restritas à sociedade política. Com isso, uma nova gestão pública, pautada nos princípios gerencialistas de cunho empresarial, passou a dominar a atmosfera estatal e a gestão educacional, que também foi atingida com tais alterações.

No terreno da sociedade civil, no qual as diferentes ideologias se encontram em permanente disputa, seja para favorecer as estratégias de construção da sua hegemonia pelos grupos subalternos ou pela manutenção desta pelas classes e frações de classe no poder, um grande número de organizações foram criadas para atuarem de modo a complementar e expandir as ações do Estado. Dentre as quais, chama-nos atenção a UNDIME, fundada no contexto interno da redemocratização brasileira, que passou a desempenhar uma funçãochave no processo de implementação e avaliação de políticas, somado à tarefa de convencer e produzir consensos. Essa instituição se legitimou como pretensa representante dos interesses coletivos ligados à construção de uma educação pública e de qualidade nos municípios brasileiros. Assim, passou a compor uma rede complexa, composta por vários atores das sociedades civil e política, bem como por organismos multilaterais.

Nesse direcionamento, a UNDIME, em seu papel de educador e por intermédio dos seus intelectuais orgânicos, tem desenvolvido contínuos processos formativos voltados aos dirigentes e equipes técnicas das secretarias municipais de Educação, a fim de promover o consentimento relativo às políticas sociais de natureza mercadológica, em geral, já definidas em outras instâncias, prevalentemente, por instituições empresariais representadas por seus aparelhos privados de hegemonia. Atuando em rede, a UNDIME organiza fóruns temáticos, seminários nacionais e regionais, publicação de cadernos, guias de orientações, manuais, plataformas digitais, além de jornais e de outros informativos, sempre associada a uma série de atores, como a Fundação Santillana da Editora Moderna, através da qual publicou o "Caderno de Orientações ao Dirigente Municipal de Educação: Fundamentos, Políticas e Práticas, alvo de algumas análises presentes neste texto. 
Como se vê, a atual sociabilidade capitalista supõe a configuração de novos arranjos econômicos, políticos e ideológicos, reverberados no campo educacional, como manifestação de interesses divergentes e contraditórios. A compreensão dessa realidade passa pelo necessário debate acerca do papel da sociedade civil na constituição do Estado, em seu sentido mais amplo, no contexto de atualização das estratégias de manutenção da hegemonia burguesa. Para isso, apesar de insuficiente, a educação exerce uma função de destaque na luta pela construção de outra sociabilidade, fundamentada não mais na exploração e alienação do trabalho, mas na sua condição ontológica, que expressa a liberdade dos sujeitos.

\section{REFERÊNCIAS}

BALL, Stephen J. Performatividade, Privatização e o Pós-Estado do Bem-Eestar. In: Dossiê: Globalização e Educação: precarização do trabalho docente. Educ. Soc., Campinas, vol. 25, n. 89, p. 1105-1126, Set./Dez. 20041105 Disponível em:

https://www.scielo.br/pdf/es/v25n89/22613.pdf.

\section{BASTOS, Remo Moreira Brito. O Banco Mundial e a Educação como Aparelho}

Ideológico na Periferia Capitalista. 2014. 149 f. Dissertação (Mestrado em Educação Brasileira) - Faculdade de Educação. Universidade Federal do Ceará. Fortaleza, 2014.

BRASIL. Instituto Nacional de Estudos e Pesquisas Educacionais Anísio Teixeira. Plano Nacional de Educação PNE 2014-2024: linha de base. Brasília, DF: Inep, 2015. 404 p.

BRASIL. Plano Diretor da Reforma do Aparelho do Estado (PDRAE). Brasília: MARE, 1995. Disponível em <www.biblioteca.presidencia.gov.br/publicacoes-

ficiais/catalogo/fhc/planodiretor-da-reforma-do-aparelho-do-estado-1995.pdf > . Acesso em 10 jul 2016. Brasília, 1995. Acesso em 10 jul 2016. Brasília, 1995.

BRASIL. Lei no 9.394, de 20 de dezembro de 1996. Estabelece as diretrizes e bases da educação nacional. Diário Oficial da União. Brasília, DF, 23 dez. 1996.

BRASIL. Plano Diretor da Reforma do Aparelho do Estado. Brasília: Presidência da República. 1996. (83p.).

BRASIL. Ministério da Educação / Secretaria de Articulação com os Sistemas de Ensino (MEC/ SASE), 2014.

BRASIL. Ministério da Educação / Estados e municípios trabalham para elaborar metas; prazo vai até julho do próximo ano. Disponível em:

http://portal.mec.gov.br/index.php?option=com_content\&view=article\&id=20786:estados-emunicipios-trabalham-para-elaborar-metas-prazo-vai-ate-julho-do-proximo-ano\&catid=222\&Itemid=86. Acesso em: 26/03/2020.

CASIMIRO, Flávio Henrique Calheiros. A nova Direita: aparelhos de ação política e ideológica no Brasil contemporâneo. $1^{a}$ ed. São Paulo: Expressão Popular. 2018. 
CATANI, Afrânio Mendes. O que é capitalismo. 34a . Ed. São Paulo: Brasiliense, 1998.

CATINI, Carolina de Roig. Privatização da Educação e Gestão da Barbárie. $1^{\text {a }}$ ed. São Paulo: Edições Lado Esquerdo. 2017.

FREITAS, Luiz Carlos de. A reforma empresarial da educação: nova direita, velhas ideias. 1 ed. São Paulo: Expressão Popular, 2018.

GRAMSCI, Antonio. Cadernos do Cárcere - Volume 3: Maquiavel, notas sobre o Estado e a política. Rio de Janeiro: Civilização Brasileira, 2000.

GRAMSCI, Antonio. O leitor de Gramsci: escritos escolhidos 1916-1935. Organização e Introdução de Carlos Nelson Coutinho. Rio de Janeiro: Civilização Brasileira, 2011. (Leitores). 375p.

HARVEY, David. Condição Pós-moderna. 12 ed. São Paulo: Loyola, 2006.

HARVEY, David. O neoliberalismo: história e implicações. 5 ed. São Paulo: Loyola, 2014.

IBGE - INTITUTO BRASILEIRO DE GEOGRAFIA E ESTATÍSTICA. As Fundações Privadas e sem Fins Lucrativos no Brasil - FASFIL. Principais Resultados. Rio de Janeiro, 2016.

MALHEIROS, Silvânia de Jesus Pina. A UNDIME - PE e a municipalização do ensino no Estado de Pernambuco. Recife: o autor, 2006. 183 f. Dissertação (Mestrado). Universidade Federal de Pernambuco. Orientação: Profa. Dra Márcia ângela da Silva Aguiar.

MARX, Karl. O capital: crítica da economia política. Livro 1. O processo de produção do capital. Volume II. Rio de Janeiro: Bertrand Brasil, 1989.

NEVES. Lúcia Maria Wanderley. Educação e Política no Brasil de Hoje. $4^{\text {a }}$ ed. - São Paulo, Cortez, 2005.

PEREIRA, Jhonata Moreira; GROSSI JUNIOR, Geraldo. A Rede de Assistência Técnica para Elaboração ou Adequação dos Planos Municipais de Educação. IX Congresso CONSAD de Gestão Pública, 2016. Disponível em http://consad.org.br/wpcontent/uploads/2016/06/Painel-37-03.pdf. Acesso em: 17 out. 2020.

POULANTZAS, Nicos. O Estado, o poder, o socialismo. $1^{\text {a }}$ ed. São Paulo: Paz e Terra, 2015.

SANTOS, Aline Veiga dos. A hegemonia do capital na rede de governança do Fundo de Financiamento Estudantil (Fies) / Aline Veiga dos Santos - 2018. 292 f.: il.; $30 \mathrm{~cm}$ Tese (Doutorado) - Universidade Católica de Brasília, 2018. Orientação: Profa. Dra. Ranilce Guimarães-Iosif

SHIROMA, Eneida Otto; EVANGELISTA, Olinda. Estado, capital e educação: reflexões sobre hegemonia e redes de governança. Revista Educação e Fronteiras On-Line, Dourados, v. 4, n. 11, p. 21-38, mai./ago. 2014. 
TARLAU, Rebeca; MOELLER, Kathryn. O Consenso por Filantropia como uma fundação privada estabeleceu a BNCC no Brasil. Currículo sem Fronteiras, v. 20, n. 2, p. 553-603, maio/ago. 2020.

UNDIME. União Nacional dos Dirigentes Municipais de Educação. Orientações ao Dirigente Municipal de Educação: fundamentos, políticas e práticas. São Paulo: Fundação Santillana, 2012.

UNDIME. União Nacional dos Dirigentes Municipais de Educação. Agenda dos cem primeiros dias - Orientações ao Dirigente Municipal de Educação. São Paulo: Fundação Santillana, 2012b.

UNDIME. União Nacional dos Dirigentes Municipais de Educação, 2020. Linha do Tempo. Disponível em: https://undime.org.br/linhadotempo/. Acesso em: 23 de abr. de 2020.

VIEGAS, Elis Regina dos Santos. O Mercado da formação continuada de professores no Brasil: a presença do empresariamento social privado. 2019. $328 \mathrm{f}$. Tese (Doutorado em Educação) - Faculdade de Ciências Exatas e Tecnologia. Universidade Federal da Grande Dourados. Dourados, 2019.

\section{SOBRE OS AUTORES:}

\section{Luciana Pedrosa Marcassa}

Professora do Centro de Ciências da Educação e do Programa de Pós-Graduação em Educação da Universidade Federal de Santa Catarina - CED/PPGE/UFSC. Líder do TMT Núcleo de Estudos sobre as Transformações no Mundo do Trabalho

(TMT/CED/UFSC/CNPq). E-mail: luciana.marcassa@ufsc.br

iD https://orcid.org/0000-0001-5313-1002

\section{Danilo Bandeira dos Santos Cruz}

Doutorando do Programa de Pós Graduação em Educação, do Centro de Educação da Universidade Federal de Santa Catarina - UFSC. Florianópolis - SC. Grupo de Pesquisa: Núcleo de Estudos sobre as Transformações no Mundo do Trabalho - TMT. É professor da Rede Estadual de Educação da Bahia. E-mail: danibande2@gmail.com

(iD http://orcid.org/0000-0001-5831-6698 